\title{
Annual survival rates of adult Red-necked Nightjars Caprimulgus ruficollis
}

\author{
MANUELA G. FORERO ${ }^{1 *}$, JOSÉ L. TELLA² \& DANIEL ORO ${ }^{3}$ \\ 'Department of Applied Biology, Estación Biológica de Doñana, Pabellón del Perú, Avda. Ma Luisa s/n, \\ 41013 Sevilla, Spain \\ ${ }^{2}$ Department of Biology, University of Saskatchewan, Saskatoon, Saskatchewan S7N OWO, Canada \\ ${ }^{3}$ Instituto Mediterráneo de Estudios Avanzados IMEDEA (CSIC-UIB), Crtra. Valldemosa, $\mathrm{km}$ 7.5, 07071 Palma de \\ Mallorca, Spain
}

\begin{abstract}
Nothing is known about the survival rates of Nightjars. Here we estimate annual survival rates of adult Red-necked Nightjars Caprimulgus ruficollis in and around the Doñana National Park, southwest Spain. During the period 1989-95, 557 adults were marked and $19.7 \%$ of them were recaptured at least once in subsequent years. Capture-recapture models were built to estimate separately survival and recapture probabilities. The final selected model showed that probabilities of recapture differed between years $(0.06-0.30)$ but not between sexes, and were independent of recapture effort. Survival was dependent on the interaction between sex and rainfall, this effect being negative for females and positive for males. However, it is not clear why rainfall influences the survival of males and females differentially due to the lack of accurate information on other life history traits. Average adult survival for the whole period was 0.74 for males (95\% CI: $0.63-0.82$ ) and 0.64 for females (95\% CI: $0.56-0.72$ ).
\end{abstract}

The estimation of survival rates is of primary importance for the study of life-history strategies and population dynamics of birds, as well as for modelling their population trends for conservation and management (Lebreton et al. 1992, 1993). Thus, survival has been studied in many groups of birds (Weimerskirch et al. 1987, Spendelow et al. 1995, Arnold \& Clark 1996, Hiraldo et al. 1996, Siriwardena et al. 1998, Oro et al. 1999) using methods of capture-mark-recapture, which account for missed individuals due to low probabilities of recapture (Lebreton et al. 1992). However, to our knowledge this life-history parameter is unknown for any species of Caprimulgiformes (120 species, del Hoyo et al. 1999), probably because their nocturnal habits, secretive behaviour and cryptic plumage make difficult their detection and capture, and thus long-term studies based on marked birds. In the present study, we provide the first estimates of survival rates for adult Red-necked Nightjars Caprimulgus ruficollis, using seven years of capture-recapture data.

The Red-necked Nightjar is a migratory Mediterranean species which feeds on aerial insects in dry

${ }^{*}$ Corresponding author.

Email: gforero@ebd.csic.es warm regions of the Iberian peninsula and northwest Africa (Cramp 1985). For this species, very little is known about any aspect of its biology or life-history traits (Cramp 1985, Gargallo 1994, Forero et al. 1995, Cuadrado \& Domínguez 1996, Forero et al. 1997, Forero \& Tella 1997) and no information is available about its population trends (SEO/BirdLife 1997). In southern Spain the breeding season lasts from April to August, females probably laying two clutches, each of two eggs. Incubation lasts 18-19 days, females probably taking the larger share, and an average of 1.2 fledglings are raised per clutch (Cuadrado \& Dominguez 1996).

\section{METHODS}

Data were collected from 1989 to 1995 in and around the Donana National Park, southwest Spain (Forero et al. 1995). This is mainly a marsh area, temporarily flooded, combined with Mediterranean scrubland and cultivated land surrounding the park. Primary productivity of this ecosystem is positively related to rainfall, which varies greatly between years (Valverde 1967). During our study period, rainfall during the breeding season ranged between 38 and $133 \mathrm{~mm}$. 
Red-necked Nightjars were captured from June to October and marked with metal leg rings. We caught the birds using a torch and a hand-net in the course of systematic nocturnal car transects along gravel roads (Forero et al. 1995). Capture effort varied annually between three and 12 nights of fieldwork (18-44 hours for year, mean $=27$ ). Sex of individuals was determined according to the size of the pale spots on wing and tail (Cramp 1985, Forero et al. 1995). We grouped birds on the basis of moult stages into two age-classes: juveniles (born during the year of capture) and adults (Gargallo 1994, Forero et al. 1995). Due to the low number of recaptures of birds marked as juveniles during the study, only adult survival was estimated.

Estimates of adult survival were calculated using separate data sets for each sex and following Jolly-Seber mark-recapture models for open populations (Lebreton et al. 1992, 1993). We used the program RELFASE (Burnham et al. 1987) to assess the goodness-of-fit of the initial models $\left(\phi_{t^{*},}, p_{t^{*}}\right)$, where survival $(\phi)$ and resighting $(p)$ probabilities are both time $(t)$ and sex $(s)$ dependent. Tests showed homogeneity between and within groups for adult data sets $(P>0.05$ for all tests). Therefore, our data were appropriate for a Jolly-Seber modelling approach, and subsequent models were fitted by the maximum likelihood method using program SURGE v5.0. We used Akaike's Information Criterion (AIC) to select the most parsimonious model, i.e. the model with the lowest AIC value (Lebreton et al. 1992). The models were considered to be statistically equivalent if the difference in AIC between models was less than 2 (see for instance Anderson et al. 1994). Models were constrained by ecological hypotheses based on factors that might affect survival or capture probabilities. The possibility that rainfall during the breeding season in year $t$ may have influenced survival until year $t+1$ was considered in the models using a logit-linear constraint (Lebreton et al. 1992): the hypothesis was that food availability (i.e. flying insect populations) was positively associated with rainfall, and in turn with adult survival, this being lower in years with lower rainfall. Several studies have recorded changes in survival of adult birds related to environmental features such as rainfall, flooding or temperature in winter (Clobert et al. 1987, Lebreton et al. 1992, Senar \& Copete 1995). Rainfall in the winter quarters has also been proved to influence survival in some migratory bird species (Kanyamibwa et al. 1990. Peach et al. 1991). Unfortunately, no accurate information is available about the location of wintering areas for Red-necked Nightjars (no recaptures were obtained in winter from 1538 birds ringed in Spain in 1973-97, Cantos \& Gómez-Manzaneque 1998), thus making it difficult to test this hypothesis properly at present. To estimate capture probability, models were also constructed which included all combinations of time and sex and the different recapture effort $(e)$ made each year, measured as the number of hours spent catching birds. A model testing for trap-dependence $(m)$ after capture was also considered (Pradel 1993).

\section{RESULTS}

During the study period, 557 adults were marked and $19.7 \%$ of them were recaptured at least once in subsequent years (Table 1). Recapture probability was not related to the number of hours spent catching birds each year (Table 2). Recapture differed between years, but not between the sexes either as an interaction or an additive effect (Table 2). Probabilities of recapture ranged between 0.06 and 0.30 (Table 3). Survival was dependent on the interaction between rainfall and sex (Table 2). The model showed that rainfall positively influenced survival for males, whereas female survival decreased when rainfall increased (Table 3, Fig. 1). The correlation of survival with rainfall was significant for both males and females $(95 \%$ confidence interval for the slope: 0.014 to 0.026 and -0.029 to -0.227 respec-

Table 1. Number of adult Red-necked Nightjars ringed and subsequently recaptured each year.

\begin{tabular}{|c|c|c|c|c|c|c|c|}
\hline \multirow[b]{2}{*}{ Year } & \multirow[b]{2}{*}{ Number ringed } & \multirow[b]{2}{*}{1990} & \multirow[b]{2}{*}{1991} & \multicolumn{2}{|c|}{ Year of recapture } & \multirow{2}{*}{1994} & \multirow{2}{*}{1995} \\
\hline & & & & 1992 & 1993 & & \\
\hline 1989 & 94 & 4 & 13 & 6 & 3 & 1 & 2 \\
\hline 1990 & 138 & - & 28 & 12 & 6 & 3 & 0 \\
\hline 1991 & 150 & - & - & 21 & 5 & 2 & 2 \\
\hline 1992 & 93 & - & - & - & 6 & 2 & 2 \\
\hline 1993 & 53 & - & - & - & - & 3 & 2 \\
\hline 1994 & 40 & - & - & - & - & - & 3 \\
\hline
\end{tabular}


Table 2. Survival models and associated biological hypotheses for Red-necked Nightjars in southern Spain. Best-fitting model is in bold. Dev, deviance of the model as given by program SURGE; np, number of identifiable parameters; AIC, Akaike information criterion computed as Dev $+2 n p$. Factors considered potentially to affect survival $(\phi)$ or capture $(p)$ probabilities were: time $(t)$, sex $(s)$, rainfall $(r)$, effort of capture $(e)$ and trap-dependence $(m)$.

\begin{tabular}{|c|c|c|c|c|}
\hline Model & Dev & $\mathrm{np}$ & AIC & Biological hypothesis \\
\hline$\phi_{t^{*} s}, p_{t^{*} s}$ & 830.77 & 20 & 870.77 & Interaction of sex with time for survival and recapture \\
\hline$\phi_{t ' s}, p_{t}$ & 835.27 & 16 & 867.27 & Interaction of sex with time for survival; recapture varied with time \\
\hline$\phi_{s}, p_{t^{*} s}$ & 840.14 & 14 & 868.14 & Survival depended on sex; interaction of sex with time for recapture \\
\hline$\phi_{t^{*} s}, p_{s}$ & 847.33 & 14 & 875.33 & Interaction of sex with time for survival; recapture depended on sex \\
\hline$\phi_{t^{*}}, p$ & 847.62 & 12 & 871.62 & Interaction of sex with time for survival; constant recapture \\
\hline$\phi_{t}, p_{t}$ & 844.83 & 10 & 864.83 & Survival and recapture depended on time \\
\hline$\phi_{s}, p_{t}$ & 844.56 & 8 & 860.56 & Survival depended on sex; recapture varied with time \\
\hline$\phi_{t}, p$ & 854.83 & 7 & 868.83 & Survival depended on time; constant recapture \\
\hline$\phi, p_{t}$ & 846.34 & 7 & 860.34 & Constant survival; recapture depended on time \\
\hline$\phi_{s}, p_{s}$ & 882.32 & 4 & 890.32 & Both survival and recapture depended on sex \\
\hline$\phi_{s}, p$ & 884.29 & 3 & 890.29 & Survival depended on sex; constant recapture \\
\hline$\phi, p_{s}$ & 886.51 & 3 & 892.51 & Constant survival; recapture depended on sex \\
\hline$\phi, p$ & 886.58 & 2 & 890.58 & Constant both survival and recapture \\
\hline$\phi_{t+s}, p_{t+s}$ & 838.60 & 14 & 866.60 & Additive effect of time and sex for both survival and recapture \\
\hline$\phi_{t+}, p_{t}$ & 835.28 & 13 & 861.28 & Additive effect of time and sex for survival; recapture varied with time \\
\hline$\phi, p_{t+s}$ & 846.18 & 8 & 862.18 & Constant survival; additive effect of time and sex for recapture \\
\hline$\phi_{s}, p_{s^{*} e}$ & 882.32 & 5 & 892.32 & $\begin{array}{l}\text { Survival depended on sex; recapture varied with the interaction of sex and } \\
\text { effort of capture }\end{array}$ \\
\hline$\phi_{s}, p_{\theta}$ & 878.83 & 4 & 886.83 & Survival depended on sex; recapture varied with effort of capture \\
\hline$\phi, p_{e}$ & 880.92 & 3 & 886.92 & Constant survival; recapture varied with effort of capture \\
\hline$\phi, p_{m+t}$ & 843.45 & 12 & 867.45 & Constant survival; recapture was trap-dependent \\
\hline$\phi_{s}, p_{s+e}$ & 876.63 & 5 & 886.63 & Survival depended on sex; additive effect of sex and effort for recapture \\
\hline$\phi, p_{s+e}$ & 880.87 & 4 & 888.87 & Constant survival; additive effect of sex and effort for recapture \\
\hline$\phi_{r}, p_{t}$ & $\mathbf{8 3 7 . 8 8}$ & 10 & 857.88 & $\begin{array}{l}\text { Survival depended on the interaction of sex and rainfall; recapture varied } \\
\text { with time }\end{array}$ \\
\hline$\phi_{r^{*} s}, p_{t+s}$ & 837.09 & 11 & 859.09 & $\begin{array}{l}\text { Survival depended on the interaction of sex and rainfall; additive effect of time and } \\
\text { sex for recapture }\end{array}$ \\
\hline$\phi_{r}, p_{t}$ & 846.33 & 8 & 862.33 & Survival depended on rainfall; recapture varied with time \\
\hline$\phi, p_{r}$ & 882.94 & 3 & 888.94 & Constant survival; recapture depended on rainfall during breeding \\
\hline$\phi_{r^{*} s_{r}} p_{r}$ & 863.63 & 5 & 873.63 & $\begin{array}{l}\text { Survival depended on the interaction of sex and rainfall; recapture varied with } \\
\text { rainfall }\end{array}$ \\
\hline
\end{tabular}

tively). Average survival for the whole period ( $\left.\phi_{\mathrm{av}}\right)$, calculated following the equation:

$$
\phi_{\mathrm{av}}=\mathrm{e}^{\operatorname{mean}\left(\ln \phi_{i}\right)}
$$

(Cormack 1964), was 0.74 for males (95\% CI: $0.63-0.82$ ) and 0.64 for females (95\% CI: $0.56-0.72$ ).

\section{DISCusSION}

The absence of information on survival rates of other Caprimulgiformes prevents us from comparing our results with other species or with other populations of the same species. Adult survival depended on the interaction between the birds' sex and rainfall during the breeding season. Differences in survival rates between sexes have been reported previously in many species of birds (Blondel et al. 1992, Francis \& Cooke 1992, Kanyamibwa et al. 1993, Horak \& Lebreton
1998). Results on adult survival of Red-necked Nightjars in southern Spain agree with the general pattern described for monogamous birds, males surviving better than females (Breitwisch 1989). However, the influence of rainfall on adult survival differed strikingly between sexes. Although very little is known about sex roles during breeding in Caprimulgiformes (Jackson 1985), several studies suggest that parental investment during incubation and brooding young chicks is higher for females than for males (Tate 1989, Fry et al. 1988, Poulin et al. 1996, Brigham \& Geiser 1997). The influence of rainfall on adult survival could be the direct consequence of higher food availability, reducing the energy investment of adults looking for food and feeding their chicks. However, while this might explain the positive correlation of rainfall with male survival, it cannot explain the negative trend for females. If females spent more time in the nest incubating the eggs and brooding chicks, their vulnerability 
Table 3. Estimated recapture and survival probabilities for adult Red-necked Nightjars in South Spain between 1989 and 1995 under the finally selected model $\left(\phi_{r^{\prime}}, p_{t}\right)$. Standard deviation (sd) and $95 \%$ confidence intervals $(\mathrm{Cl})$ are also shown.

\begin{tabular}{lccc}
\hline Year & Estimate & sd & $\mathrm{Cl}$ \\
Recapture & & & \\
1990 & 0.059 & $0.264\left(\times 10^{-3}\right)$ & $0.058-0.059$ \\
1991 & 0.304 & $0.430\left(\times 10^{-3}\right)$ & $0.227-0.394$ \\
1992 & 0.186 & $0.276\left(\times 10^{-3}\right)$ & $0.137-0.246$ \\
1993 & 0.113 & $0.237\left(\times 10^{-3}\right)$ & $0.074-0.168$ \\
1994 & 0.077 & $0.181\left(\times 10^{-3}\right)$ & $0.048-0.121$ \\
1995 & 0.078 & $0.165\left(\times 10^{-3}\right)$ & $0.051-0.117$ \\
Male survival & & & \\
$1989-90$ & 0.706 & $0.537\left(\times 10^{-1}\right)$ & $0.591-0.799$ \\
$1990-91$ & 0.832 & $0.525\left(\times 10^{-1}\right)$ & $0.704-0.912$ \\
$1991-92$ & 0.511 & $0.313\left(\times 10^{-1}\right)$ & $0.450-0.572$ \\
$1992-93$ & 0.874 & $0.473\left(\times 10^{-1}\right)$ & $0.750-0.942$ \\
$1993-94$ & 0.862 & $0.492\left(\times 10^{-1}\right)$ & $0.735-0.933$ \\
$1994-95$ & 0.746 & $0.552\left(\times 10^{-1}\right)$ & $0.624-0.839$ \\
Female survival & & & \\
$1989-90$ & 0.775 & $0.232\left(\times 10^{-1}\right)$ & $0.727-0.818$ \\
$1990-91$ & 0.574 & $0.475\left(\times 10^{-1}\right)$ & $0.479-0.663$ \\
$1991-92$ & 0.910 & $0.529\left(\times 10^{-2}\right)$ & $0.899-0.920$ \\
$1992-93$ & 0.465 & $0.554\left(\times 10^{-1}\right)$ & $0.360-0.574$ \\
$1993-94$ & 0.501 & $0.533\left(\times 10^{-1}\right)$ & $0.398-0.604$ \\
$1994-95$ & 0.726 & $0.299\left(\times 10^{-1}\right)$ & $0.664-0.781$ \\
\hline
\end{tabular}

to predation might be higher than that of males. In the Doñana area there is a rich and dense community of raptors and carnivores which mainly prey upon Rabbits Oryctolagus cuniculus (Valverde 1967). It has recently been discovered that in the study area heavy rainfall strongly decreases the availability of rabbits because of the flooding of their burrows (Palomares et al. in press). Under low Rabbit densities, predators

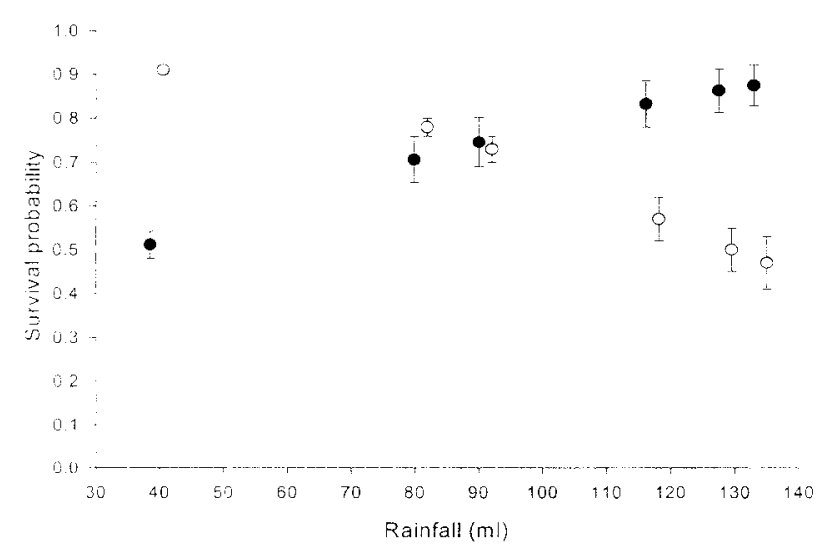

Figure 1. Estimated survival probabilities for adult Red-necked Nightjars in southern Spain plotted against rainfall during the breeding season for study period (1989-1995) under the model $\left(\phi_{r^{*} s}, p_{t}\right)$. Mean \pm sd for males $(\bullet)$ and females $(0)$ are represented. enlarge their dietary niche width increasing the pressure on secondary foraging resources (Fedriani et al. 1998), thus potentially affecting more female Nightjars.

Recapture probabilities for adult Red-necked Nightjars varied with time independently of the variable annual catching effort. That variation could be the result of random temporary emigration or dispersal to less accessible areas (see also Sandland \& Kirkwood 1981, Pradel 1993), although nightjars seem to show high philopatry (Jackson 1985, Poulin et al. 1996). Inter-year variation in recapture probability could also result from heterogeneity in recapture rates between individuals (see also Cézilly et al. 1996, Prévot-Julliard et al. 1998). Further research is needed on most aspects of the biology and ecology of this and other Nightjar species before these and other basic questions on their life histories can be answered.

We are grateful to L. Garcia, J. Calderón and the personnel at the Reserva Biológica de Doñana for their help in fieldwork. Comments from Will Peach and an anonymous referee greatly improved the manuscript. Manuela G. Forero and José L. Tella were supported by both pre-doctoral and post-doctoral grants from the Spanish MEC.

\section{REFERENCES}

Anderson, D.R., Burnham, K.P. \& White, C.G. 1994. AlC model selection in overdispersed capture-recapture data. Ecology 75 : 1780-1793.

Arnold, T.W. \& Clark, R.G. 1996. Survival and philopatry of female dabbling ducks in Southcentral Saskatchewan. J. Wildl. Manage. 60: 560-568.

Blondel, J., Pradel, R. \& Lebreton, J.-D. 1992. Low fecundity insular Blue Tits do not survive better as adults than high fecundity mainland ones. J. Anim. Ecol. 61: 205-213.

Breitwisch, R. 1989. Mortality patterns, sex ratios, and parental investment in monogamous birds. Curr. Ornithol. 6: 1-50.

Brigham, R.M. \& Geiser, F. 1997. Breeding biology of Australian Owlet-nightjars Aegotheles cristatus in Eucalypt Woodland. Emu 97: 316-321.

Burnham, K.P., Anderson, D.R., White, G.C., Brownie, C. \& Pollock, K.H. 1987. Design and analysis methods for fish survival experiments based on release-recapture. Am. Fish. Soc. Monogr. 5: $1-437$.

Cantos, F.J. \& Gómez-Manzaneque, A. 1998. Informe sobre la campaña de anillamiento de aves en España. Año 1997. Ecologéa 12: 251-401

Cézilly, F., Viallefont, A., Boy, V. \& Johnson, A.R. 1996. Annual variation in survival and breeding probability in Greater Flamingos. Ecology 77: 1143-1150.

Clobert, J., Lebreton, J.D. \& Allaine, D. 1987. A general approach to survival rate estimation by recaptures or resightings of marked birds. Ardea 75: 133-142.

Cormack, R.M. 1964. Estimates of survival from the sighting of marked animals. Biometrika 51: 429-438. 
Cramp, S. (ed.) 1985. The Birds of the Western Palearctic, Vol. 4. Oxford: Oxford University Press.

Cuadrado, M. \& Domínguez, F. 1996. Phenology and breeding success of Red-necked Nightjar Caprimulgus ruficollis in Southern Spain. J. Ornithol. 137: 249-253.

del Hoyo, J., Elliot, A. \& Sargatal, J. 1999. Handbook of the Birds of the World, Vol. 5. Barcelona: Lynx Edicions.

Fedriani, J.M., Ferreras, P. \& Delibes, M. 1998. Dietary response of the Eurasian badger, Meles meles, to a decline of its main prey in the Doñana National Park. J. Zool., Lond. 245: 214-218.

Forero, M.G., Tella, J.L. \& Garcia, L. 1995. Age related evolution of sexual dimorphism in the Red-necked Nightjar (Caprimulgus ruficollis). J. Ornithol. 136: 447-451.

Forero, M.G. \& Tella, J.L. 1997. Sexual dimorphism, plumage variability and species determination in nightjars: the need for further examination of the Nechisar Nightjar Caprimulgus solala. Ibis 139: 407-409.

Forero, M.G., Tella, J.L. \& Gajón, A. 1997. Absence of blood parasites in the Red-necked Nightjar. J. Field Ornithol. 68: 575-579.

Francis, Ch.M. \& Cooke, F. 1992. Sexual differences in survival and recovery rates of lesser snow geese. $J$. Wildl. Manage. 56: 287-296.

Fry, C.H., Keith, S. \& Urban, E.K. 1988. The Birds of Africa, Vol. 3. London: Academic Press.

Gargallo, G. 1994. Flight feather moult in the Red-necked Nightjar Caprimulgus ruficollis. J. Avian Biol. 25: 119-124.

Hiraldo, F., Negro, J. J., Donázar, J. A. \& Gaona, P. 1996. A demographic model for a population of the endangered Lesser Kestrel in southern Spain. J. Appl. Ecol. 33: 1085-1093.

Horak, P. \& Lebreton, J.-D. 1998. Survival of adult Great Tits Parus major in relation to sex and habitat; a comparison of urban and rural populations. Ibis 140: 205-209.

Jackson, H.D. 1985. Aspect of the breeding biology of the Fierynecked Nightjar. Ostrich 56: 263-277.

Kanyamibwa, S., Schierer, A., Pradel, R. \& Lebreton, J.-D. 1990. Changes in adult annual survival rates in a western European population of the White Stork Ciconia ciconia. Ibis 132: 27-35.

Kanyamibwa, S., Bairlein, F. \& Schierer, A. 1993. Comparison of survival rates between populations of the White Stork Ciconia ciconia in Central Europe. Ornis Scand. 24: 297-302.

Lebreton, J.-D., Burnham, K.P., Clobert, J. \& Anderson, D.R. 1992. Modelling survival and testing biological hypotheses using marked animals: A unified approach with case studies. Ecol. Monogr. 62: 67-118.

Lebreton, J.-D., Pradel, R. \& Clobert, J. 1993. The statistical analysis of survival in animal populations. Trends Ecol. Evol. 8: 91-95.
Oro, D., Pradel, R. \& Lebreton, J.-D. 1999. Food availability and nest predation influence life history traits in Audouin's gull, Larus audouinii. Oecologia 118: 438-445.

Palomares, F., Delibes, M., Revilla, E., Calzada, J. \& Fedriani, J.M. In press. Spatial ecology of the Iberian Lynx and abundance of the European Rabbit in Southwestern Spain. Wildlife Monogr.

Peach, W., Baillie, S. \& Underhill, L. 1991. Survival of British Sedge Warblers Acrocephalus schoenobaenus in relation to west African rainfall. Ibis 133: 300-305

Poulin, R.G., Grindal, S.D. \& Brigham, R.M. 1996. Common Nighthawk (Chordeiles minor). The Birds of North America: 213. Washington, DC: The American Ornithologists' Union.

Pradel, R. 1993. Flexibility in survival analysis from recapture data: handling trap-dependence. In Lebreton, J.-D. \& North, P.M. (eds) Marked Individuals in the Study of Bird Populations: 29-37. Basel: Birkhäuser Verlag.

Prévot-Julliard, A.-C., Lebreton, J.-D. \& Pradel, R. 1998. Re-evaluation of the adult survival of a long-tived bird species, the Black-headed Gull (Larus ridibundus) in presence of recapture heterogeneity. Auk 115: 85-95.

Sandland, R.L. \& Kirkwood, G.P. 1981. Estimation of survival in marked populations with possibly dependent sighting probabilities. Biometrika 68: 531-541.

SEO/BirdLife 1997. Atlas de las Aves de España (1975-1995). Barcelona: Lynx Edicions.

Senar, J.C. \& Copete, J.L. 1995. Mediterranean House Sparrows (Passer domesticus) are not used to freezing temperatures: an analysis of survival rates. J. Appl. Stat. 22: 1069-1074.

Siriwardena, G.M., Baillie, S.R. \& Wilson, J.D. 1998. Variation in the survival rates of some British passerines with respect to their population trends on farmland. Bird Study 45: 276-292.

Spendelow, J.A., Nichols, J.D., Nisbet, I.C.T., Hays, H., Cormons, G.D., Burger, J., Safina, C., Hines, J.E. \& Gochfeld, M. 1995. Estimating annual survival and movement rates of adults within a metapopulation of Roseate Terns. Ecology 76: 2415-2428.

Tate, P. 1989. The Nightjar. Haverfordwest: Shire Natural History, C.I. Thomas \& Sons Ltd.

Valverde, J.A. 1967. Estructura de una Comunidad de Vertebrados Terrestres. Madrid: CSIC

Weimerskirch, H., Clobert, J. \& Jouventin, P. 1987. Survival in five southern albatrosses and its relationship with their life history. $\mathrm{J}$. Anim. Ecol. 56: 1043-1055.

Received 17 September 1999; revision accepted 19 June 2000 